A short paper based on these results appears in:

Medynskiy, Y., \& Bruckman, A. (2007). The Effects of Conversations with Regulars and Administrators on the Participation of New Users in a Virtual Learning Community. Proc. Computer Supported Collaborative Learning. New Brunswick, NJ.

\title{
The Effects of Conversations with Regulars and Administrators on the Participation of New Users in a Virtual Learning Community
}

\author{
Yevgeniy "Eugene” Medynskiy, Amy Bruckman \\ College of Computing \\ Georgia Institute of Technology \\ Email: eugenem@gatech.edu, asb@cc.gatech.edu
}

\begin{abstract}
Recent interest in synchronous collaborative learning environments prompts an examination of users' participation, social roles, and social interactions in these spaces. We analyze new users' participation rates on MOOSE Crossing, a collaborative educational environment that has been operating for over ten years. We examine how interactions with MOOSE Crossing regulars - highly active users who set the tone for the community - and its administrators, may influence the participation of new users. New users who conversed with regulars or administrators soon after joining are found to exhibit more social activity and stay involved with MOOSE Crossing longer than new users who did not. Regulars are apparently better at eliciting participation than administrators, but a synergistic effect is also detected - new users who interacted with both administrators and regulars exhibit especially high rates of participation.
\end{abstract}

\section{Introduction}

Virtual environments that allow for synchronous, multi-user participation have recently received much attention from the computer-supported collaborative learning (CSCL) community. These online spaces are seen by many as engaging for students, allowing for peer collaboration and support, and, in general, being conducive to a host of educational activities that would otherwise be difficult to realize. In some of cases, these online environments foster the formation of a community of active members who engage each other, motivate newcomers, and participate in long-term educational activities. For example, the virtual world of Second Life (http://www.secondlife.com/), designed to be built by its inhabitants, is filled with significant technical and artistic accomplishments created by its users, and shows some of the potential of these systems as constructionist (Harel \& Papert, 1991) learning environments.

A number of synchronous, multi-user learning environments have recently been deployed to augment science curricula for children in classroom settings. One of these, Quest Atlantis, allows groups of students in classrooms or after-school centers to participate in a host of directed educational activities (Barab, Thomas, Dodge, Carteaux \& Tuzun, 2005). Quest Atlantis was successfully deployed in a fourth grade classroom, and was shown to engage its users, allowed them to participate in scientific discourse and develop a richer understanding of science (Barab, Sadler, Heiselt, Hickey \& Zuiker, in press). Another immersive virtual world, River City, is a virtual, graphical city "world" that engages groups of children to participate in problem-based scientific inquiry. During deployments, children who used the system showed greater engagement with the subject and an improvement in their scientific knowledge, as compared to students learning from a paper-based control curriculum (Ketelhut, Dede \& Clarke, 2006).

In the service of adult education, multi-user online environments can be used to bring together dispersed groups of professionals into a community. A successful example of an online community of professionals is the Tapped In (http://www.tappedin.org/) project for teacher professional development. Tapped In participants help establish a community of practice for their profession, provide support to each other, and contribute to group discourse (Schlager, Fusco \& Schank, 2002). Another online community, MediaMOO, allowed media researchers to interact and casually collaborate in a text-based online virtual world (Bruckman \& Resnick, 1995). Using, exploring, and reconstructing this world was found to be meaningful and engaging for its residents.

A number of reasons are often cited for why users seek out and participate in multi-user virtual worlds, or are encouraged to do so by educators. Users can find themselves engaged by a virtual world - its graphics, media content, or the activities available within (Ondrejka, 2004). Also, members of an online group or community can, and often do, provide social support. This can come in the form of technical support, emotional support ("I found that confusing too!"), a ready source of role models, and an appreciative audience for completed work (Bruckman, 
1998). Finally, users of virtual environments can experiment with alternate identities (Turkle, 1995) and, especially in the case of children, decision-making and self-organization (Bers \& Chau, 2006).

Some virtual multi-user learning environments demand participation from their users - for example, because they are deployed in a classroom setting. Others are populated with self-motivated individuals, or some combination of self-motivated and mandatory participants. Leaving students free to choose whether to participate may increase motivation for some, but others may exercise the option not to participate (Bruckman, 2000). Understanding factors that encourage and elicit participation in self-motivated online communities and environments is a common goal in recent CSCW research (Beenen et al, 2004; Joyce \& Kraut, 2006; Lampe \& Johnston, 2005). In this paper we examine the effects that early social interactions seem to have on new users' eventual level of participation in one particular self-motivated multi-user learning environment, MOOSE Crossing.

\section{MOOSE Crossing}

MOOSE Crossing is a text-based, multi-user, educational online environment (MUD) for children. The environment and its kid-friendly programming language, MOOSE, were developed to provide a space where children could learn to program and practice creating writing in a social environment. A range of activities is available to MOOSE Crossing users, including exploring different in-world areas, communicating with others, and interacting with in-world objects and places. The focus of the environment, however, is to get users to create new inworld objects and places. Using the MOOSE programming language, players can create interactive objects, such as pets or flying carpets, or design places, such as tree houses or paradise islands.

MOOSE Crossing came online in 1995 and has been active for over 10 years. Over this time it has attracted over 1000 users. Its target demographic is children between the ages of eight and thirteen, but it has also attracted younger children, older teenagers, and adults. Its younger users come from a broad range of backgrounds - homeschooled children, groups of children in traditional classroom settings, and children enrolled in after-school programs. MOOSE Crossing also has had a number of adult users, including parents, teachers, and other professionals involved in research or education. These usually join to supervise children, provide help, or offer themselves as role models.

Project developers and others involved in creating and maintaining MOOSE Crossing also play an active role in its community. These system administrators are often logged in, and work to keep order, welcome new users, and provide help on using and exploring the environment. Many of them are well-known among MOOSE Crossing residents. Over the entire run of MOOSE Crossing, approximately twenty-five administrators participated on the service - hanging out, talking to other users, and building up their own in-world spaces and objects. Of these, about ten can be considered highly active participants, and are among some of the most active MOOSE Crossing users.

Most young users of MOOSE Crossing are self-motivated, and come and go as they please. Among these users, there is a highly skewed distribution of participation and achievement (Bruckman, Edwards, Elliott \& Jensen, 2000). A few strongly motivated individuals spend a great deal of time logged in - creating objects, exploring, and interacting with others. Most users, however, are low- or medium-frequency users - logging in only a small number of days and programming few, if any, in-world objects.

\section{Participation in Online Communities}

Uneven levels of commitment and participation from users is a commonly noted aspect of many online spaces and communities. For example, while large numbers of individuals make minor contributions to open source development projects, the majority of work is nonetheless usually done by a small group of highly committed individuals (Mockus, Fielding \& Herbsleb, 2000; Nakakoji, Yamamoto, Nishinaka, Kishika \& Ye, 2002). Many Usenet newsgroups also show a highly skewed distribution of participation. Fisher, Smith, and Welser found a small numbers of highly active participants and very large numbers of infrequent participants in the newsgroups they surveyed (2006).

In order to be able to sustain themselves over time, however, groups need to be able to recruit and retain new members (Kim, 1995; McGrath, 1984). Recent research has looked at explaining variations in retention rates of new users in online communities, especially with respect to what factors influence first-time contributors to return to contribute again. In online forums, feedback and responses from other group members make first-time posters more 
likely to post again (Joyce \& Kraut, 2006), and increase the speed of posting again (Lampe \& Johnston, 2005), as compared to posters who receive no response. Beenen and colleagues have also shown success in using results from social psychology to motivate low-frequency contributors to take a more active role in an online group by highlighting the contributors' individual uniqueness and providing them with challenging goals (2004).

In addition to these results, a number of social features in synchronous online learning environments have been proposed and deployed in an attempt to increase participation from new members (Kim, 1995). The designers of Tapped In, for example, established a Community Help Desk that is always staffed by an administrator or volunteer (Schlager, Fusco \& Schank, 2002). These individuals welcome new users, provide quick answers to technical questions, and support users as they adjust to the environment.

We look to the work of Ray Oldenburg to deepen our understanding of the highly active, core members of online groups. Oldenburg uses the term "third place" to describe informal social places outside of the two common social environments of work and home (1999). A key feature of a third place is its "regulars" - individuals who are often present and set its tone and atmosphere. Some informal online spaces can be similarly described as third places (Steinkuehler \& Williams, 2006). They, too, have a core of regulars who frequent the space, and do a lot to set its tone in terms of social norms, conversational themes, and other aspects. By looking at the active, motivated cores of online groups and communities through the lens of regulars, we can start expressing the types of influence they can potentially have on new members.

As a final note, we wish to address the issue of participation as a precursor to learning. Lurking is a common phenomenon in many online groups (Nonnecke \& Preece, 2000), and, indeed, lurkers usually find themselves benefited by simply watching the activities of others (Nonnecke \& Preece, 1999). In a constructivist learning community like MOOSE Crossing, however, active participation leads to the most benefit for the kids using it. Learning can be viewed as a process of transformation of participation, moving from peripheral to more central roles (Lave \& Wenger, 1991). Thus, we feel that the kids who actively explore MOOSE Crossing, interact with others, and build more and more impressive in-world objects are the ones who are getting the most out of their experience. In our analysis we are careful not to dismiss low-activity users as not receiving any benefit, but still recognize that greater metrics of participation - more frequent use of the system, more social interaction, etc. - are likely to be associated with higher achievement in the types of skills the MOOSE Crossing environment is designed to foster.

\section{Participation in MOOSE Crossing}

Our analysis of participation on MOOSE Crossing comes from the availability of approximately $3.7 \mathrm{~GB}$ of logs recorded by the system over the period of time between October 1995 and December 2003. During this time, 1204 users logged in to MOOSE Crossing, including kids, system administrators, and other adults. Of these, 856 were minors under the age of eighteen (most distributed between the ages of eight and thirteen). Each of these users corresponds to a single individual - creating an account on MOOSE Crossing was an involved process, with an identity verification step, and no user requested multiple accounts. Everything that happens on MOOSE Crossing is logged, with written consent from parents and assent from kids.

For each MOOSE Crossing user, we compiled a list of statistics: the total number of days the user had logged into the service, the total number of communication commands the user had used, and a chronologically ordered list of every conversational partner the user had. We did not include the total amount of time users spent logged in, as it is possible to be logged in through the MOOSE Crossing client but not actually be present at the keyboard. MOOSE Crossing has two types of communication commands - room-level communications, which any player within the speaker's surroundings can hear, and direct communications, which are heard only by the player they are directed at. In our analysis, we consider a player to have had a conversation with another player if the first ever made a communicative utterance that the other could hear. This gave us a list of directed relationships, which we then processed, removing all relationships in which one user is listed as having a conversation with another user, but the later isn't listed as having a conversation with the former. While this is a simple heuristic, it is one that is easy to comprehend and works in practice. In a brief informal examination of our data, we saw that in a great majority of cases, when a user said something to, or in the presence of, another user they went on to have what could easy be interpreted as a conversation, even if sometimes a brief one. 
As we compiled metrics of participation for MOOSE Crossing users, we looked for its "regulars" - highly active, social kids who were well-known to the other players, and to the administrators. Though it was easy to pick out candidates for regulars, there was no clear cut-off we could see between regulars and non-regulars, as there were users all along the spectrum from very low participation to very high participation. Keeping in mind our goal to try to determine whether interacting with regulars was likely to encourage participation in new MOOSE Crossing users, we decided to set an arbitrary cut-off point for which users we could consider "regulars" for the purposes of our study. We picked the ten users with the highest numbers of days logging in to be our regulars. These users were also some of the top socializers, as measured by numbers of conversational partners they had and total numbers of communication commands they entered. Each of the users on this list was also recognized as an important participant by one of the study's co-authors, a long-time MOOSE Crossing administrator. We picked ten regulars for two reasons: firstly, it allowed us to explore just how influential a small number of top users can be, and secondly it is also similar to the number of highly active administrators MOOSE Crossing has had over the years. To verify our selection criteria, we ran parallel analyses using the top fifteen and top twenty participants as our "regulars," as well. These runs gave results consistent with those that will be presented in this paper. However, for the rest of this paper we will refer only to the top ten participants as "regulars."

Eights of the regulars were girls. One of the regulars initially started participating as part of an in-school program, and the rest joined on their own. Three of the regulars were home-schooled, and the rest were elementary or middle school students when they joined. The average age of regulars, at the time they joined MOOSE Crossing, was ten years with the youngest being eight and the oldest thirteen.

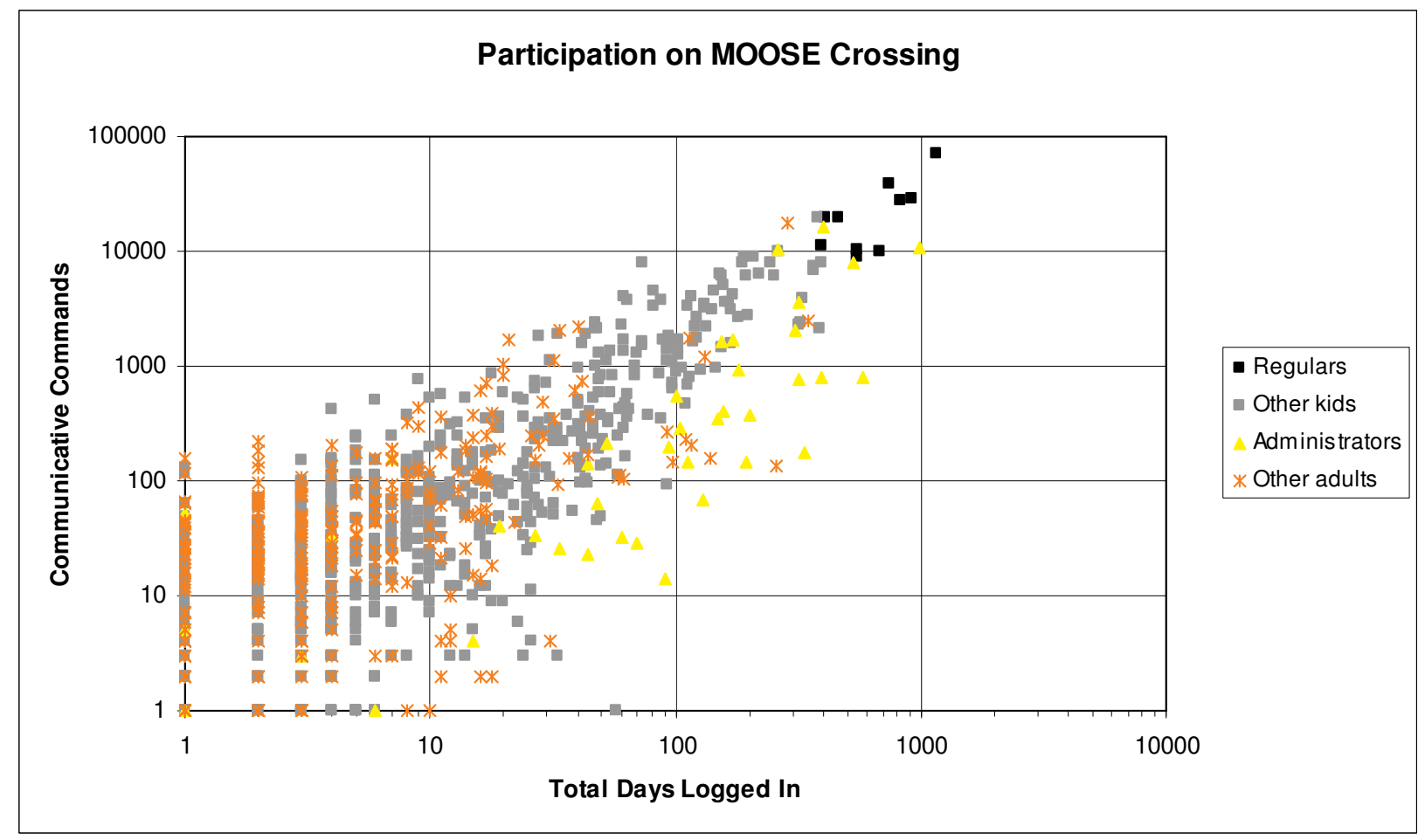

Figure 1. Measures of participation for different types of MOOSE Crossing users.

Figure 1 shows participation metrics for different types of MOOSE Crossing users on logarithmic axes. There is large number of users in the lower-left corner of the graph, who logged into the system only once or twice, and issued less than one hundred communication commands. However, it is interesting to note that a number of users did hit well over one hundred communication commands in a single day. Towards the upper-right corner, there are also many users who logged in over 100 days: approximately 50 kids (including all of the regulars), over 20 administrators, and a few adults (all of them parents of other highly active users). The majority of users are somewhere in the middle - spending between a few and a few dozen days on the system, and entering between fifty and a few thousand communication commands. Table 1 further summarizes this data, showing the means and the 
medians of the different MOOSE Crossing player types. Since the distribution of the data is highly skewed, we find that the mean and median together provide a better description of the data than either alone.

Table 1: Activity summary for different MOOSE Crossing users.

\begin{tabular}{|l|l|l|l|l|l|l|l|l|l|}
\hline \multirow{2}{*}{ Group } & \multirow{2}{*}{$\mathbf{N}$} & \multicolumn{4}{|l|}{ Communication Commands } & \multicolumn{3}{l|}{ Number of Days Logging In } \\
\cline { 3 - 10 } & & Median & Mean (St Dev) & Min & Max & Median & Mean (St Dev) & Min & Max \\
\hline Regulars & 10 & 19653 & $24583(19175)$ & 8870 & 71322 & 555 & $670(245)$ & 397 & 1154 \\
\hline Other kids & 846 & 20 & $377(1327)$ & 0 & 19724 & 4 & $22(49)$ & 1 & 393 \\
\hline Administrators & 34 & 214 & $1816(3822)$ & 23 & 16641 & 130 & $194(206)$ & 1 & 994 \\
\hline Other Adults & 317 & 37 & $292(1520)$ & 0 & 17810 & 4 & $24(67)$ & 1 & 578 \\
\hline
\end{tabular}

A previous study of MOOSE Crossing has shown that overall, approximately twenty five percent of commands a user issues are communication commands (Bruckman, Jensen \& DeBonte, 2002). This number varies with gender, with girls being slightly more likely to communicate than boys. The same study also shows that programming achievement on MOOSE Crossing is directly related to time spent on the system as a whole. As kids spend more time in MOOSE Crossing, they read more of the programming tutorials, meet other individuals whose creations inspire them to create their own, and spend more time exploring and learning the MOOSE programming language. Thus, we take our two metrics of participation - the number of communication commands entered, and the total number of days logging into MOOSE Crossing - to be valid proxies for the measure of a user's programming achievement and overall benefit from participation. While there certainly isn't a direct, formulaic relationship between our proxy metrics and some measure of "learning," we do suggest that an increase in one or both metrics is desirable.

\section{Effects of Conversations on the Participation Metrics of New Users}

We now examine the relationship between the first few conversations new MOOSE Crossing users participated in, and their eventual level of participation. In particular, we look at the make-up of new users' first few conversational partners, and how it correlates with the metrics of participation we gathered. Are users who initially encounter MOOSE Crossing regulars likely to have greater levels of participation, and if so, in what way? Were administrators, most of whom had the explicit goal of helping and encouraging new users, successful, and if so, how successful were they?

In our first set of analysis, we considered only the first three conversational partners of new users. We compiled all MOOSE Crossing users who were not adults, administrators, or regulars. We located the first time these users were seen on the system, and recorded the first three users they conversed with, as per our earlier definition of conversation. Users who had less than three conversational partners in total were removed from the dataset. In total, 505 MOOSE Crossing users had at least three conversational partners, and we divided these into four groups: those whose first three conversational partners included at least one regular and at least one administrator (group RA, $\mathrm{N}=31$ ); those whose first three conversational partners included at least one administrator but no regulars (group $\mathrm{A}, \mathrm{N}=86$ ); those whose first three conversational partners included at least one regular but no administrators (group $\mathrm{R}, \mathrm{N}=113$ ); and those whose first three conversational partners included neither regulars nor administrators (group $\mathrm{X}, \mathrm{N}=275$ ). A breakdown of these groups' activity metrics, as given by the total number of communication commands entered and total number of days logging into MOOSE Crossing, is given in Table 2.

Table 2: Activity metrics for kids with at least three conversational partners.

\begin{tabular}{|l|l|l|l|l|l|}
\hline \multirow{2}{*}{ Group Name } & \multirow{2}{*}{$\mathbf{N}$} & \multicolumn{2}{|l|}{ Communication Commands } & \multicolumn{2}{l|}{ Number of Days Logging In } \\
\cline { 3 - 6 } & & Median & Mean (St Dev) & Median & Mean (St Dev) \\
\hline X & 275 & 41 & $446(1611)$ & 6 & $26(53)$ \\
\hline A & 86 & 58 & $824(1675)$ & 10 & $39(54)$ \\
\hline R & 113 & 138 & $733(1560)$ & 21 & $47(70)$ \\
\hline RA & 31 & 305 & $1312(2296)$ & 18 & $46(75)$ \\
\hline
\end{tabular}


Trends in Table 2 suggest that talking to either administrators or regulars soon after starting with MOOSE Crossing is linked with an increase in participation, both in terms of sociability and the length of time eventually spent on the system. Talking to at least one regular seems to bring about a significant increase in these metrics - the medians of both metrics for groups R and RA are quite a bit higher than that of group A. The means are also higher (especially for the number of communication commands in group RA), but the high variance makes it difficult to speculate about these differences.

To test if the differences in means were indeed significant, we ran an ANOVA with Tukey's HSD post-hoc analysis on this dataset. Because the distributions of the numbers of communication commands and numbers of days logged in for each group were highly right-skewed, we logarithmically transformed our data to bring it closer to a normal distribution. The ANOVA indeed showed that the four groups differed in terms of the mean amount of communication commands their members used $\left(\mathrm{F}_{3,501}=18.579, \mathrm{p}<0.01\right)$, and the mean number of days they logged in $\left(\mathrm{F}_{3,501}=12.041, \mathrm{p}<0.01\right)$. Tukey's HSD post-hoc analysis showed that each of the groups A, R and RA, whose members talked to at least one regular or at least one administrator, performed significantly better than group $\mathrm{X}$, whose members talked to neither ( $\mathrm{p}<0.05$ in all cases). In addition, group RA used a significantly higher mean number of communication commands than group A $(\mathrm{p}<0.05)$.

To verify these results, we also ran the nonparametric Kruskal-Wallis test on the original, non-transformed data. The Kruskal-Wallis test performs the same kind of analysis as the ANOVA, but does not make any assumptions about the distribution of the data within each group. Like the results above, this test also suggested that the groups differed in both total number of communication commands $\left(\chi^{2}=56.06, \mathrm{df}=3, \mathrm{p}<0.01\right)$ and on the total number of days logged in $\left(\chi^{2}=36.366, \mathrm{df}=3, \mathrm{p}<0.01\right)$. The mean ranks of each group, according to this test, are given in Table 3. Overall, they show the same results as the ANOVA: groups A, R, and AR all improve over group X on both metrics and, in addition, group RA improves over group A in terms of number of communication commands.

Table 3: Kruskal-Wallis mean ranks for kids with at least three conversational partners

\begin{tabular}{|l|l|l|l|l|}
\hline Group Name: & X & A & R & RA \\
\hline Mean Rank for Communication Commands: & 212 & 267 & 317 & 346 \\
\hline Mean Rank for Number of Days Logged In: & 218 & 278 & 305 & 304 \\
\hline
\end{tabular}

This first set of results suggests a difference between the way interactions with administrators and interactions with regulars affect the eventual participation levels of new MOOSE Crossing users. To further investigate these effects, we decided to split up new users based on the exact numbers of administrators and regulars they talked to. For this analysis, we considered all users who had at least five conversational partners. There were 457 users who fit this criterion, and we divided them into groups based on how many administrators and regulars there were in their first five conversational partners. We removed any group with less than ten members, which left us with nine groups: a group whose members had no administrators and no regulars in their first five conversational partners (group 0A-0R, $\mathrm{N}=219$ ); a group whose members had one administrator and no regulars (group 1A-0R, $\mathrm{N}=50$ ); a group whose members had two administrators and no regulars (group $2 \mathrm{~A}-0 \mathrm{R}, \mathrm{N}=11$ ); no administrators and one regular (group 0A-1R, $\mathrm{N}=69$ ); no administrators and two regulars (group $0 \mathrm{~A}-2 \mathrm{R}, \mathrm{N}=19$ ); no administrators and three regulars (group 0A-3R, N=13); one administrator and one regular (group 1A-1R, N=29); two administrators and one regular (group 2A-1R, $\mathrm{N}=10$ ); and one administrator and two regulars (group $1 \mathrm{~A}-2 \mathrm{R}, \mathrm{N}=14$ ). These groups and their mean and median metrics of participation are shown in Table 4.

A number of interesting trends can be seen in Table 4. Talking to any number of regulars, but no administrators, as with groups $0 \mathrm{~A}-1 \mathrm{R}, 0 \mathrm{~A}-2 \mathrm{R}$, and $0 \mathrm{~A}-3 \mathrm{R}$, seems to increase participation as measured by both communication commands entered and the number of days logging into the system. The increase in participation metrics for users in group $0 \mathrm{~A}-3 \mathrm{R}$ is especially high. Talking to administrators but not regulars (groups $1 \mathrm{~A}-0 \mathrm{R}$ and $2 \mathrm{~A}-0 \mathrm{R})$ also seems to increase participation, though to a lesser extend than if talking only to regulars. Here, too, more seems to be better, as members of group 2A-0R outperform those of group 1A-0R on all measures. Users in groups $1 \mathrm{~A}-1 \mathrm{R}, 1 \mathrm{~A}-2 \mathrm{R}$, and $2 \mathrm{~A}-1 \mathrm{R}$, who talked to both administrators and regulars early on, consistently perform as well as or better than the others, suggesting a synergistic effect of talking to both administrators and regulars early on. 
Table 4: Activity metrics for kids with at least five conversational partners.

\begin{tabular}{|l|l|l|l|l|l|}
\hline \multirow{2}{*}{ Group Name } & \multirow{2}{*}{$\mathbf{N}$} & \multicolumn{3}{|l|}{ Communication Commands } & \multicolumn{2}{l|}{ Number of Days Logging In } \\
\cline { 3 - 6 } & & Median & Mean (St Dev) & Median & Mean (St Dev) \\
\hline 0A-0R & 219 & 40 & $382(1583)$ & 5 & $23(49)$ \\
\hline 1A-0R & 50 & 44 & $599(1755)$ & 9 & $38(67)$ \\
\hline $2 A-0 R$ & 11 & 63 & $854(1142)$ & 14 & $45(58)$ \\
\hline 0A-1R & 69 & 138 & $615(1459)$ & 18 & $48(75)$ \\
\hline 0A-2R & 19 & 148 & $892(1500)$ & 29 & $58(79)$ \\
\hline 0A-3R & 13 & 576 & $2237(3036)$ & 63 & $75(72)$ \\
\hline 1A-1R & 29 & 519 & $1212(1727)$ & 25 & $52(60)$ \\
\hline 2A-1R & 10 & 525 & $2602(2960)$ & 27 & $90(107)$ \\
\hline 1A-2R & 14 & 624 & $873(1072)$ & 40 & $46(43)$ \\
\hline
\end{tabular}

Similarly to the first analysis, we performed an ANOVA and Tukey's HSD post-hoc analysis on a logtransformed copy of this data to statistically test the trends noted above. There were significant differences in the means across the nine groups for both communication commands $\left(F_{8,425}=13.116, p<0.01\right)$ and for the number of days logging in $\left(\mathrm{F}_{8,425}=8.740, \mathrm{p}<0.01\right)$. Tukey's HSD post-hoc analysis showed that each of the groups whose members spoke to at least one regular - 0A-1R, 0A-2R, 0A-3R, 1A-1R, 1A-2R, and 2A-1R - had a significantly higher mean of communication commands and days that they logged in than group 0A-0R ( $\mathrm{p}<0.05$ in each case). However, neither group 1A-0R nor 2A-0R, whose members talked to at least one administrator but not to regulars, had a significant increase in either metric over group 0A-0R, at the 0.05 level. Additionally, each of groups $0 \mathrm{~A}-3 \mathrm{R}$, $1 \mathrm{~A}-1 \mathrm{R}, 1 \mathrm{~A}-2 \mathrm{R}$, and $2 \mathrm{~A}-1 \mathrm{R}$ used a significantly higher mean number of communication commands used than group $1 \mathrm{~A}-0 \mathrm{R}(\mathrm{p}<0.05$ in all cases $)$.

We also ran the nonparametric Kruskal-Wallis test on a non-transformed copy of our dataset to see if the results there matched the results of the ANOVA and Tukey's HSD post-hoc analysis. The tests confirmed that the differences in both total number of communication commands $\left(\chi^{2}=88.886, \mathrm{df}=8, \mathrm{p}<0.01\right)$ and on the total number of days logged in $\left(\chi^{2}=63.024, \mathrm{df}=8, \mathrm{p}<0.01\right)$., and the mean ranks for each group are given in Table 5. Here results are similar in spirit to the results given by the ANOVA, but a few differing points can be noted. Groups 1 A-0R and 2AOR, whose members talked to administrators but not to regulars within their first conversational partners, have a higher mean rank than group 0A-OR. This suggests that, indeed, talking to administrators but not regulars is still at least somewhat linked to higher metrics of participation on MOOSE Crossing. In fact, the mean rank of group 2AOR for the number of days logging in is nearly the same as that for group 0A-1R. Groups whose members talked to both at least one administrator and at least one regular also perform better than all other groups. Again, this suggests a synergistic effect, as members of group 1A-1R have higher mean ranks for both metrics of participation than either group $0 \mathrm{~A}-2 \mathrm{R}$ or $2 \mathrm{~A}-0 \mathrm{R}$. Finally, group $0 \mathrm{~A}-3 \mathrm{R}$ performs exceptionally well, its mean ranks being higher than any other group.

Table 5: Kruskal-Wallis mean ranks for kids with at least five conversational partners.

\begin{tabular}{|l|l|l|l|l|l|l|l|l|l|}
\hline Group Name: & $0 \mathrm{~A}-0 \mathrm{R}$ & $1 \mathrm{~A}-0 \mathrm{R}$ & 2A-0R & 0A-1R & 0A-2R & 0A-3R & 1A-1R & $2 \mathrm{~A}-1 \mathrm{R}$ & $1 \mathrm{~A}-2 \mathrm{R}$ \\
\hline $\begin{array}{l}\text { Mean Rank } \\
\text { for Comm. } \\
\text { Commands: }\end{array}$ & 173 & 193 & 237 & 253 & 281 & 348 & 314 & 319 & 331 \\
\hline $\begin{array}{l}\text { Mean Rank } \\
\text { for \# of Days } \\
\text { Logged In: }\end{array}$ & 174 & 223 & 256 & 260 & 270 & 309 & 281 & 302 & 286 \\
\hline
\end{tabular}

In the next section, we discuss the two sets of statistical results presented here. We focus on possible reasons for why members of some groups seemed to show greater overall participation in MOOSE Crossing than 
members of other groups. Finally, we end by following up with our regulars - what did they feel were key reasons for participating in MOOSE Crossing? What motivated them?

\section{Discussion}

We can begin to explore the results which emerge from the analyses presented in the previous section by looking at the participation metrics individually, and invoking our familiarity with the MOOSE Crossing environment. Invariably, new MOOSE Crossing users who interacted with highly active, social MOOSE Crossing residents - its regulars - were likely to show higher levels of participation, both in terms of the amount of communicating they did, and in terms of how many days they logged into the environment. The trends also suggest that talking to a greater number of regulars elicited more participation - the means and medians for both of our metrics of participation consistently increase from group $0 \mathrm{~A}-1 \mathrm{R}$, to group $0 \mathrm{~A}-2 \mathrm{R}$, to group $0 \mathrm{~A}-3 \mathrm{R}$. Regulars are especially good at eliciting social participation from the users they meet - the medians for all groups where a user talked to at least one regular are high, suggesting that most of the kids in these groups engaged in long chat sessions. We note from experience that regulars are often excited to talk to other MOOSE Crossing users, and other users (especially new users) come to them for help with various aspects of the system. In other words, the kids who are regulars are likely to chat with and befriend other kids (Bruckman, 2000). Often, this friendliness also results in the new users spending more time logging into MOOSE Crossing to play and socialize with her new friend(s) - in all groups whose users talked to regulars, when the mean and median of the number of communication commands are high, the mean and median number of days logged into MOOSE Crossing is correspondingly high.

Talking to administrators is also beneficial - most trends in the data point to this conclusion. On their own, however, administrators don't seem to be as good elicitors of participation, especially of social participation (measured by number of communication commands), as regulars. Administrators aren't as likely to immediately try to friend new MOOSE Crossing users: they are older and often busy with their own work (including back-end maintenance of the site). They don't hang out or look for opportunities to chat as much as the regular kids do. They do, however, serve the important role of providing supervision, encouragement, and technical help to new users.

The result that we found most interesting is the apparent synergistic effect that talking to both administrators and regulars has on the participation metrics of new MOOSE Crossing users. Groups whose members conversed with both administrators and regulars within their first few conversational partners consistently performed well, as judged by both the number of communication commands they entered and the number of days they logged in. The types of social support provided by administrators and regulars seem to be complementary, and together strongly engage and motivate new users.

\section{MOOSE Crossing Regulars: Their Perspective}

For another perspective on motivation and participation on MOOSE Crossing, we attempted to seek out our regulars' opinions. We sent out a brief email containing the following question to each of our ten regulars: "What factors do you feel encourage a new user to stay on MOOSE [Crossing] and become active?" Unfortunately, most of our regulars have since stopped using the email addresses they registered with - many of the emails bounced or the recipients did not respond. (We continue to try to contact them.) The two regulars who did respond to our question (both of whom are now college students), however, provided thoughtful and interesting responses. Both stressed the importance of support from other MOOSE Crossing users early on in their exploration the environment. One regular wrote:

I remember when I was nine, I was a little overwhelmed by the plethora of text scrolling by on my screen, but I was curious and therefore willing to give MOOSE Crossing a shot.... What really helped was when a fellow player suddenly appeared on my first day and helped me understand everything I was seeing. Without a curious mind and the help of a new friend, I might have been too intimidated by the surface of the MUD and never discovered the boundless possibilites [sic] offered inside.

Our second respondent focused on how engaging with the community motivated her to keep participating. (We were surprised that she mentioned exactly the issues we were exploring in this paper, unprompted.) 
My guess is that the primary factor determining whether a new user will remain on MOOSE and become active is whether the user feels like they've become part of the community. I felt very attached to MOOSE because I felt like people there wanted me to be there. I enjoyed the creative element a great deal, but I created objects primarily so that they could be appreciated by the community....I'm guessing that you could probably correlate whether new users interacted with people early on with whether they became regulars.

Our informal discussions with these two regulars are consistent with our quantitative findings. These two regulars remember benefiting from meeting others early in their own experiences with MOOSE Crossing, and consciously tried to help others in the same way later on.

\section{Conclusion}

We believe that the results we have presented in this paper have both practical and theoretical implications. Practically, they speak to the importance of supporting, fostering, and rewarding an online community's regulars. In synchronous, self-motivated, collaborative learning environments, like MOOSE Crossing, regulars often act as an unofficial welcoming committee and support desk for new users. In these spaces, other human users command much more attention than tutorials, on-line help, or any other inanimate form of support provided by the system's designers and organizers. The more we understand the informal support provided by regulars, the more we as designers of online systems can help support these key roles.

From a theoretical perspective, this work raises interesting issues about peer-to-peer support in learning communities, both face-to-face and online. Why does support from peers prove more valuable than support from adults in this context? Could this hold true in other learning environments? We also found that support from both a peer and an adult proved more valuable than either alone. Will this hold true elsewhere as well? Are these potentially useful heuristics for designers? Pushing deeper, if these things are indeed more generally applicable, why? Does this in any way inform our fundamental understanding of communities of practice and social support for learning in CSCL systems? These are intriguing questions to address in future work.

\section{References}

Barab, S., Thomas, M., Dodge, T., Carteaux R., \& Tuzun, H. (2005). Making Learning Fun: Quest Atlantis, A Game Without Guns. Educational Technology Research and Development, 53(1), pp. 86-107.

Barab, S., Sadler, T., Heiselt, C., Hickey, D., \& Zuiker, S. (in press). Relating Narrative, Inquiry, and Inscriptions: Supporting Consequential Play. Journal of Science Education and Technology.

Beenen, G., Ling, K., Wang, X., Chang, K., Frankowski, D., Resnick, P. \& Kraut, R. E. (2004). Using Social Psychology to Motivate Contributions to Online Communities. In Proceedings of CSCW 2004 (pp. 212221). Chicago, IL, 6-10 November 2004.

Bers, M. U., \& Chau, C. Fostering Civic Engagement by Building a Virtual City. Journal of Computer-Mediated Communication, 11(3), article 4. http://jcmc.indiana.edu/vol11/issue3/bers.html

Bruckman, A. (1997). MOOSE Crossing: Construction, Community, and Learning in a Networked Virtual World for Kids. Unpublished PhD, MIT.

Bruckman, A. (1998). Community Support for Constructionist Learning. Computer Supported Collaborative Work: The Journal of Collaborative Computing, 7, pp. 47-86.

Bruckman, A. (2000). Situated Support for Learning: Storm's Weekend with Rachael. Journal of the Learning Sciences, 9(3), pp. 329-372.

Bruckman, A., Edwards, E., Elliott, J. \& Jensen, C. (2000). Uneven Achievement in a Constructionist Learning Environment. In Proceedings of ICLS 2000. Ann Arbor, MI, 14-17 June 2000.

Bruckman, A., Jensen, C. \& DeBonte, A. (2002). Gender and Programming Achievement in a CSCL Environment. In Proceedings of CSCL 2002. Boulder, CO, January 2002.

Bruckman, A., \& Resnick, M. (1995). The MediaMOO Project: Constructionism and Professional Community. Convergence, l(1), pp. 94-109.

Fisher, D., Smith, M., and Welser, H. (2006). You Are Who You Talk To: Detecting Roles in Usenet Groups. In Proceedings of HICSS 2006. Kauai, HI, January 2006.

Harel, I. \& Papert, S. (1991). Situating Constructionism. In I. Harel, and S. Papert (Eds.) Constructionism. Norwood, NJ: Ablex Publishing. 
Joyce, E. \& Kraut. R. E. (2006). Predicting Continued Participation in Newsgroups. Journal of Computer-Mediated Communication, 11(3), article 3. http://jcmc.indiana.edu/vol11/issue3/joyce.html

Ketelhut, D. J., Dede, C., Clarke, J., \& Nelson, B. (2006). A multi-user virtual environment for building higher order inquiry skills in science. Paper presented at the American Educational Research Association, San Francisco, CA, 7-11 April 2006.

Kim, A. J. (2000). Community Building on the Web. Berkeley, CA: Peachpit Press.

Lampe, C. \& Johnston, E. (2005). Follow the (Slash) dot: Effects of Feedback on New Members in an Online Community. In Proceedings of GROUP 2005 (pp. 11-20). Sanibel Island, FL, 6-9 November 2005.

Lave, J. \& Wenger, E. (1991). Situated Learn ing: Legitimate Peripheral Participation. Cambridge University Press.

McGrath, J. (1984). Groups: Interaction and Performance. Englewood Cliffs, NJ: Prentice Hall.

Mockus, A., Fielding, R. T. \& Herbsleb, J. D. (2000). A Case Study of Open Source Development: The Apache Server. In Proceedings of ICSE 2000 (pp. 263-272). Limerick, Ireland, June 2000.

Nakakoji, K., Yamamoto, Y., Nishinaka, Y., Kishika, K. \& Ye, Y. (2002). Evolution Patterns of Open-Source Software Systems and Communities. In Proceedings of the International Workshop on Principles of Software Evolution (pp. 76-85). Orlando, FL, 19-20 May 2002. New York, NY: ACM Press.

Nonnecke, B., \& Preece, J. (1999). Shedding light on lurkers in online communities. Paper presented at the Ethnographic Studies in Real and Virtual Environments: Inhabited Information Spaces and Connected Communities. Edinburgh, Scotland, 24-26 January 1999.

Nonnecke, B., \& Preece, J. (2000). Lurker Demographics: Counting the Silent. In Proceedings of CHI 2000 (pp.7380). The Hague, The Netherlands, 1-6 April 2000.

Oldenburg, R. (1999). The Great Good Place: Cafes, Coffee Shops, Bookstores, Bars, Hair Salons, and Other Hangouts at the Heart of a Community. New York, NY: Marlowe \& Company.

Ondrejka, C. (2004). Aviators, Moguls, Fashionistas and Barons: Economics and Ownership in Second Life. Gamasutra. Retrieved 27 Nov., 2006, from http://www.gamasutra.com/resource_guide/20040920/ ondrejka_01.shtml

Schlager, M. S., Fusco, J., \& Schank, P. (2002) Evolution of an On-line Education Community of Practice. In A. Renninger, and W. Shumar (Eds.) Building Virtual Communities. Cambridge University Press.

Steinkuehler, C. \& Williams, D. (2006). Where Everybody Knows Your (Screen) Name: Online Games as "Third Places". Journal of Computer-Mediated Communication, 11(4), article 1. http://jcmc.indiana.edu/vol11/ issue4/steinkuehler.html

Turkle, S. (1995). Life on the Screen. New York, NY: Simon \& Schuster.

\section{Acknowledgments}

The authors thank Moira Burke, Jason Day, and Edward Clarkson for their help with statistics. Thanks also to the members of the Electronic Learning Communities Lab at Georgia Tech for their helpful feedback. Finally, a big thanks to all of the MOOSE Crossing alumni! 